\title{
La mediación frente a condiciones laborales inicuas
}

\author{
Mediation against iniquitous work conditions
}

Luz Marina Ramón Monje*

*https://orcid.org/0000-0001-6342-8715

Universidad Simón Bolívar, Colombia

\section{Resumen}

La mediación al interior de las organizaciones se ha ido posicionando en razón a su efectividad. Este artículo de investigación presenta un abordaje cualitativo al fenómeno de las condiciones laborales inicuas y analiza la viabilidad, por parte de sujetos expertos, del uso de la mediación como vía no sólo a la resolución de estos conflictos que son cotidianos, sino también de la dinamización de las relaciones interpersonales en pro de una óptima cultura organizacional.

Palabras clave: Mediación Laboral, Conflictos Interpersonales, Condiciones Inicuas, Condiciones Inequitativas, Métodos Alternos.

\section{Abstract}

Mediation within organizations has been positioning itself due to its effectiveness. This research article presents a qualitative approach to the phenomenon of iniquitous working conditions and analyzes the viability, by expert subjects, of the use of mediation as a way not only to resolve these conflicts that are everyday, but also to dynamize of interpersonal relationships in favor of an optimal organizational culture.

Key words: Labor Mediation, Interpersonal Conflicts, Iniquitous Conditions, Inequitable Conditions, Alternative Methods. 


\section{INTRODUCCIÓN}

La mediación ha logrado posicionarse en diferentes ámbitos debido a su carácter flexible, dinámico, ergonómico y económico, etc. son ampliamente reconocidos sus efectos positivos traducidos no sólo en el acuerdo sino también en el logro de mejores relaciones interpersonales, credibilidad en los procesos no jurídicos, celeridad en el logro de establecimiento de puentes de comunicación y mejora notable de ambientes de interrelación en general.

Este artículo constituye un abordaje cualitativo realizado a 16 expertos en temas organizacionales, de salud mental laboral y mediación, con dos entrevistas estructuradas se buscó como objetivo analizar el uso de la mediación frente a condiciones laborales inicuas.

Se realizó un minucioso debate en torno a los riesgos para el sujeto y la organización de no atender de manera adecuada y oportuna los conflictos suscitados por condiciones laborales inicuas, así como la imperante necesidad de buscar una alternativa para hacerles frente. Al final, se presenta a la mediación como la opción idónea.

\section{MARCO TEÓRICO}

\section{EL CONFLICTO LABORAL Y SUS EFEC- TOS ORGANIZACIONALES}

\section{Nociones básicas sobre conflicto organi-} zacional

La interacción, intercambio y comunicación entre las personas no es armónica por de- fecto, existen variables en constante tensión que hacen impredecible la calidad de los vínculos y sentidos construidos en común (Ramón \& Gorjón, 2019). Entre más segmentado sea un grupo social es más factible determinar las manifestaciones de estos procesos, especialmente si existe una meta o propósito que una a las personas en su cotidianidad, por lo que es, en teoría, un panorama más certero en las organizaciones. Esto no anula la existencia de choques de intereses y/o deseos entre los integrantes de un equipo de trabajo, tampoco elimina sus efectos, las diferencias que pasan a la dimensión práctica no son ajenas a nadie. A este tipo de confrontaciones se les denomina conflictos, qué si bien son inevitables, tampoco deben ser la constante al interior de una organización.

Es prudente señalar que, si bien los conflictos son sinónimo de inconvenientes o problemas, este no es el caso en cada posible escenario:

Derivada de esta acepción negativa del conflicto, existen numerosas definiciones todas ellas en el mismo sentido (pelea, angustia, batalla...), pero si el interés de las partes es resolver el conflicto, resultará más adecuado emplear el término conflicto desde una perspectiva positiva y entenderlo como una situación enriquecedora (Paradinas, 2019).

Interés es la base de las acciones al interior de una organización, incluyendo los conflictos, pero al caer dentro de la dimensión de lo práctico, es necesario tomar en cuenta el 
sentido que orienta los comportamientos, es decir, la comunicación. Las motivaciones, consecuentes de las significaciones que cada integrante, desarrolla sobre su entorno, herramientas, compañeros y funciones, son los pilares de cualquier proceso de comunicación interpersonal dentro de una organización, independientemente de que genera armonía o conflictos. Inclusive, el ejercicio de la comunicación impacta directamente en la satisfacción y desempeño de los colaboradores, siendo uno de los componentes primordiales en el funcionamiento de cualquier organización.

Existen definiciones de comunicación concebidas como un proceso mecánico, instrumental y hasta administrativo, centrado en el intercambio de información o contenidos. Tomamos una noción de comunicación edificada desde la interacción para la producción de sentido y lazos interpersonales, con énfasis en el rol activo de las personas involucradas:

La palabra comunicación supone participación, interrelación, interacción con la comunidad o con el entorno en el que una persona se encuentra para satisfacer sus necesidades y desarrollar sus proyectos. La comunicación está dirigida a personas y equivale a establecer un proceso de interacción social que puede ser directo o mediado, a través de medios de comunicación tradicionales y no tradicionales. (Galarza, González, \& Quichimbo, 2013).

Éste componente interactivo de la comunicación puede ser tanto el catalizador de conflictos, pero en términos de soluciones, reducir los choques a inconvenientes de comunicación, puede ser reduccionista. Los conflictos son maleables en la organización, con capacidad de transformarse positiva o negativamente dentro de un marco de tiempo corto. La comunicación debe adaptarse a las particularidades de la situación para ser efectiva la hora de reducir la magnitud de una confrontación hasta que esta se pueda solucionar, por lo que es indispensable tener claridad sobre sus orígenes.

\section{Causas de los conflictos en la organiza- ción}

Contar con desacuerdos y disensos, puede ser parte de la raíz de los conflictos, pero es a su vez parte de la solución, debido a que estos son escenarios propicios para iniciar diálogos, elemento esencial para poder mediar y superar cualquier conflicto (Castro, 2018).

La estructura organizacional, el discurso y hasta los acuerdos simbólicos al interior de la organización también constituyen ese entramado, pudiendo ser a su vez posibles causas de conflicto al interior de la organización y al mismo tiempo, comprenden un campo de acción entre ellos. El clima organizacional, con decenas de definiciones, puede gestionarse dependiendo del contexto, pero se requiere una perspectiva humana y comunicativa para poder lidiar con conflictos dentro de una organización.

El clima en un cualquier grupo organizacional puede tener una orientación marcada hacia si el grupo ofrece todas las posibilidades del caso para que el 
personal se desarrolle dentro de la organización (orientación hacia las personas); o, por el contrario, tienen prioridad los objetivos organizacionales (grupo orientado hacia sus objetivos corporativos). De igual forma, cabría examinar la flexibilidad del grupo en las relaciones con su entorno; o, si por el contrario intenta controlar la situación actual, perdiendo la oportunidad de dejarse influir por el ambiente (contexto de un país), y buscar una adaptabilidad permanente (...) (Ramos, 2020).

Que tan flexible es la organización y se convierte en un factor sobre qué tanto puede afrontar sus conflictos para poder no sólo superarlos, sin aprender sobre los mismos. Las vulnerabilidades son expuestas a través de conflicto, de ahí que apreciarlas y aproximarse a los mismos como oportunidad, no sólo como un problema, permite sintonizarse con el contexto que la organización misma viva. Si hay debilidades que generen conflictos, es probable que exista una disonancia entre los intangibles de la organización y las prácticas diarias ejercidas por sus integrantes.

Inclusive, estos detonantes de los conflictos pueden tener ramificaciones que trasciendan de los integrantes de la organización y su magnitud impacte a los públicos externos. De ahí la importancia de gestionar los cambios necesarios para lidiar con un conflicto, con una perspectiva articulada entre la dimensión interna y externa de la organización:

El área de comunicación deberá administrar estos conflictos tratando de minimizar los problemas de reputación interna y externa, y rápidamente Marketing deberá trabajar en un fuerte reposicionamiento de la organización, ambos trabajando fuertemente en conjunto, yendo en una misma dirección, con mensajes claros y certeros hacia el público objetivo. El fin es claro: detener y dejar en el olvido el mal trago cuanto antes, sino una catástrofe puede afectar irreparablemente la historia de la compañía y por ende su reputación. (Arango, 2011).

Esto es una medida de prevención para mantener la reputación e intangibles que reposan en públicos externos con mínimas afectaciones. Tener claridad de los altercados previos, otorga la capacidad de no sólo reaccionar con situaciones no favorables de carácter externo, sino ser proactivos al respecto. Por todo lo anterior, los conflictos en la organización pueden ser nocivos o benéficos, no sólo de forma interna, sino externa, convirtiéndose en catalizadores de un cambio profundo, y no puramente efímero.

\section{Efectos e impacto del conflicto}

Indistintamente de la condición del conflicto, su primer y multilateral efecto en la organización es el cambio. Una constante de las organizaciones es que se ve catalizada por las confrontaciones y choque de criterios o comportamientos, suscitando una transformación más volátil, con menos control. Justamente el control es uno de los diagnósticos que puede arrojar un conflicto. Qué tanto se tiene al interior de la organización, si éste fue de hecho uno de los catalizadores, el tipo de liderazgo ejercido es efectivo o no, 
el bienestar de los colaboradores es ideal, su trato es digno, entre muchas otras aristas. Cómo se le aproxime, asuma y atienda al conflicto por parte de los integrantes de la organización que ostenten el liderazgo, resultara vital si el cambio generado por los conflictos es será o no benéfico para la organización.

Ahora bien, el liderazgo al interior de la organización no tiene una relación absoluta con los conflictos, pero tampoco es, una gestión ajena a provocar o, en ciertos casos específicos, ser la fuente concreta de las confrontaciones. De ahí la importancia de la comunicación, de entender el sentido de la situación y como esta afecta los lazos interpersonales de los colaboradores, como también puede que el conflicto en sí mismo surgiera por las mismas. Una visión prospectiva, no reactiva y pasiva, es la necesaria para poder afrontar altercados potenciales:

El liderazgo es un fenómeno universal que depende de valores, creencias, normas e ideales propios de una determinada cultura, razón por la cual los aspectos culturales afectan la forma en que se ejerce el liderazgo, las metas trazadas, las estrategias utilizadas para lograrlas, la percepción que tengan los seguidores sobre el actuar del líder, el intercambio de actividades, de información y recursos dentro y fuera de las organizaciones, todo ello se aproxima a los planteamientos de los modelos ecológicos de cultura organizacional, desde los cuales es posible explicar el comportamiento de las organizaciones. (Robles, Contreras, Barbosa, \& Juárez, 2013).
Los actos de los líderes de la organización, indistintamente del nivel jerárquico que ostenten en la organización, tienen un impacto directo en cómo se resuelve o profundiza el conflicto, afectando a semejante y grupos de interés por igual. Esto implica una medida de responsabilidad, no sólo laboral, sino social cuando confrontaciones o problemas se presentan. La comunicación juega nuevamente un rol vital, ya que comprender el sentido de las acciones propias y ajenas, implica también medir las consecuencias y efectos de estas:

Ser responsable va más allá de sólo cumplir normas o leyes y de adecuarse a las mismas, implica revisarse primero de manera individual y después colectivamente; así pues, la responsabilidad individual se vincula con la libertad de las personas de demostrar un comportamiento ético. El ejercicio de la libertad no sólo es modificar hábitos, costumbres o formas de vida, es gestionar interrelación e intervenir en asuntos colectivos más allá de intereses particulares (...) (Sánchez \& Cabrera, 2021).

Es así como los conflictos son reflejo de la comunicación, cultura, clima y armonía de la organización, por lo que comprenderlos de forma integral, es clave para poder no sólo solucionarlos, sino entender a los colaboradores holísticamente y mejorar así el flujo de trabajo.

\section{La mediación en el contexto organizacio- nal}

Las diferencias, choques de creencias y criterios son algunas de las causas probables 
de conflictos al interior de una organización. Con una diversidad de orígenes, existe una proporcional cantidad de medidas para gestar su respuesta y solución, con grados de efectividad variables. Siguiendo ese orden de ideas, la solución debe partir de la misma base, de la forma en que crean, producen sentido los integrantes de la organización para relacionarse entre ellos, en la que se pueda escuchar de todos, cuáles son los puntos en tensión y de esta manera sacar conclusiones del conflicto.

Mediar un conflicto no es una tarea sencilla por el grado de complejidad que estas confrontaciones ostentan debido a su rol como construcción social de sentido, pero esto no significa que sea imposible, por el contrario, existe una larga tradición científica al respecto. Hay una etapa de conciliación dentro de la mediación (Cedalise, 2020), al punto que existen pautas legales al respecto, las cuales pueden ser adaptadas para el contexto de la organización en aras de encontrar una resolución óptima:

La conciliación se define como un MASC mediante el cual "un número determinado de individuos, trabados entre sí por causa de una controversia jurídica, acuerdan componerla con la intervención de un tercero neutral -conciliador- quién, además de proponer fórmulas de acuerdo, da fe de la decisión a la que se llegue e imparte su aprobación, siendo el acuerdo final obligatorio y definitivo para las partes que concilian" 1. De manera general, no particularmente la administrativa, ha sido reconocida en nuestra legisla- ción desde los inicios de nuestra vida republicana (Carrillo \& Gómez, 2020).

Dicha figura externa y neutral tiene una responsabilidad considerable, al tener que escuchar a todas las partes involucradas en el conflicto, pero también por la necesidad que tiene de familiarizarse con la cultura y comunicación de la organización, de manera que no generen conclusiones prematuras sobre los sucesos problemáticos; se pretende contar una persona cuya óptica sea abierta, flexible e imparcial para encontrar la solución idónea y que permita establecer armonía entre los colaboradores (Gorjón, 2017).

Dentro de dicho contexto, herramientas e instrumentos pueden ser necesarios para establecer los diálogos entre los colaboradores que instigaron o se vieron involucrados en el conflicto, denotando la importancia del criterio a la hora de identificar las necesidades y tomar la decisión adecuada sobre que recursos usar para alcanzar el objetivo (Gorjón, 2020). Es necesario comprender la multitud de situaciones y circunstancias interrelacionadas de la complejidad correspondiente a la organización.

No obstante, dos aspectos fundamentales destacamos en la categoría de mediaciones múltiples: el conocimiento y el contexto. Si los agentes desarroIlan conocimientos específicos en sus experiencias tecnológicas, es también cierto que los contextos ejercen determinaciones importantes sobre cómo las tecnologías son percibidas, adoptadas y utilizadas, y cómo desde allí estas se 
materializan en distintas configuraciones identitarias. $Y$ en tanto la digitalización promueve intrincadas vinculaciones entre la televisión y los tics, se diluye toda posición binaria entre "viejos" y "nuevos" medios, para constituir en cambio escenarios interactivos, complejos y multideterminados (Fernández, 2016).

\section{Autogestión y comunicación}

Si bien es imprudente considerar que cada uno de los integrantes de la organización puede ser mediador potencial de los conflictos que puedan gestarse en su organización, el empoderamiento alrededor de su rol dentro del equipo contribuye a que direccione sus prácticas hacía el objetivo común: el bienestar organizacional. Dialogar para construir un criterio sobre la autonomía propia, identificación de situaciones conflictivas, cultiva un sentido de realización y seguridad como integrante del equipo de trabajo, y contribuye a un estado mental y emocional más sólido.

Los efectos colaterales individuales del conflicto se disminuyen al integrar la autogestión y el empoderamiento dentro de las prácticas y cultura organizacional, de manera que no es un detalle menor a considerar durante la implementación de un proceso de mediación, inclusive, líderes legitimados por colaboradores, puede que ya estén aplicando acciones con esta perspectiva por mero entendimiento performativo de las necesidades humanas del equipo. De ahí que esto no debe ser una práctica reactiva por parte de los líderes de la organización, sino que debe organizarse y planificarse para que no sólo sea exitosa, sino que oriente a los integrantes de la organización hacía el objetivo común.

La búsqueda de información constituye una forma de emancipación de los seres humanos. Representa la capacidad de crear y desplegar su propia cadena de suministro de información, de conocimientos y de entretenimiento $\mathrm{Di}$ cha capacidad de buscar, seleccionar, editar la información, siguiendo pautas propias y utilizando los medios disponibles, permite comprender la independencia del individuo de los contenidos masificados. Ahora puede buscarlos y está dispuesto a hacerlo. (Márquez-Romero \& Moret-Barillas, 2021, pág. 198).

A partir de esto, es factible establecer que el potencial de transformación del conflicto ya se estuviera aplicando, distintos actores dentro de la organización asumen roles activos y enfocados para el bienestar de todo el equipo. Dichas prácticas no sólo se deben implementar para el corto plazo, sino también para que se engranen dentro de la comunicación, sentido y cultura organizacional, de manera que disminuyan el impacto y magnitud de conflictos futuros. La planificación estratégica, implementación de protocolos de intercambio de información, escenario y oportunidades para la expresión, así como comunicación, son etapas que se deben estructurar antes de llevarse a la práctica si se quiere llegar a la meta.

Los líderes en la gestión de la comunicación estratégica son importantes para la organización, 
debido a que la comunicación, es fundamental y estratégica para las organizaciones, debido a la competencia global y a la rápida expansión de las nuevas tecnologías de la información y de la comunicación. Ellos pueden enfrentar el cambio e influenciar a los seguidores, mediante la motivación y la inspiración, para conseguir las metas comunes. (Londoño-Proaño, 2019)

\section{METODOLOGÍA}

Esta investigación es cualitativa de alcance descriptivo, se realizó bajo el paradigma fenomenológico que permite ver la realidad desde su naturaleza subjetiva y cambiante, profundizando en el conocimiento de la misma. Como técnica cualitativa se utilizó la entrevista estructurada con expertos, la cual permite seleccionar de manera estratégica a los actores que en un ejercicio dialógico y mediante unas preguntas guía, ofrezcan información nutrida sobre las variables de estudio (Sáenz \& Tamez, 2014) así:

\section{Tabla 1. Población, muestra y unidades de análisis}

\begin{tabular}{|l|l|l|}
\hline POBLACIÓN & MUESTRA & UNIDAD DE ANÁLISIS \\
\hline $\begin{array}{l}\text { Entrevista A: Investigadores y acadé- } \\
\text { micos, profesionales con experiencia } \\
\text { en armonía, el mundo del trabajo y } \\
\text { de las organizaciones, mediadores } \\
\text { en conflictos. }\end{array}$ & $\begin{array}{l}\text { Muestreo intencionado con } 10 \\
\text { expertos: } \\
\text { 1. Experto en talento humano. } \\
\text { 2. Experto en mediación. }\end{array}$ & $\begin{array}{l}\text { Mediación } \\
\text { Organizacional. } \\
\text { El conflicto Laboral } \\
\text { Interpersonal. }\end{array}$ \\
\hline $\begin{array}{l}\text { Entrevista B: Investigadores y acadé- } \\
\text { micos en salud mental laboral. }\end{array}$ & $\begin{array}{l}\text { Muestreo intencionado con } \\
6 \text { expertos en salud mental } \\
\text { laboral. }\end{array}$ & $\begin{array}{l}\text { Mediación } \\
\text { Organizacional. } \\
\text { Lo Inicuo en las } \\
\text { Organizaciones }\end{array}$ \\
\hline
\end{tabular}

Fuente: Elaboración propia.

La atención al factor humano, mental y comunicacional, son indispensables para resolver el conflicto en el momento, para equilibrar el equipo de tal manera que este no sea superado por los problemas, y preparando a sus integrantes en la mediación para gestionar futuros conflictos y apropiarse con mayor legitimidad de las metas de la organización.
Los profesionales incluidos en la investigación cuentan con más de 10 años de experiencia profesional en campos de Gestión del Talento Humano, Salud Mental Laboral, Gestión del Riesgo Psicosocial, Comités de Convivencia Laboral, Investigación Científica Asociada. Se contó con la participación de profesionales en los campos de la Psicología, Administración de Empresas, Seguridad 
y Salud en el Trabajo, y Abogacía; todos con títulos posgraduales afines al campo de las organizaciones y en actividad laboral vigente.

Dada la especificidad de los perfiles aquí descritos, se abordaron profesionales de diferentes lugares de Colombia, bajo la premisa de que todos cuentan con la formación y experticia idónea para proveer respuestas a las preguntas de la entrevista.

El diseño de las preguntas se realizó siguiendo parámetros metodológicos y teóricos, que permitieron plantear preguntas abiertas, de fácil comprensión para los entrevistados para develar el objeto de estudio, una primera propuesta se relaciona a continuación:

\section{Tabla 2. Relación unidad de análisis y preguntas de la entrevista.}

\begin{tabular}{|c|c|}
\hline Unidad de Análisis & Preguntas Entrevista Grupo A \\
\hline \multirow[t]{3}{*}{$\begin{array}{l}\text { Conflicto Laboral } \\
\text { Interpersonal }\end{array}$} & $\begin{array}{l}\text { ¿Cuáles considera son las condiciones inequitativas y/o injustas en el } \\
\text { sitio de trabajo? }\end{array}$ \\
\hline & $\begin{array}{l}\text { ¿Cree usted que las personas entran en conflicto a razón de estas con- } \\
\text { diciones? }\end{array}$ \\
\hline & ¿Cómo cree usted que afecta a las personas este fenómeno? \\
\hline \multirow[t]{4}{*}{$\begin{array}{l}\text { Mediación } \\
\text { Organizacional }\end{array}$} & $\begin{array}{l}\text { De los elementos que usted considera construyen la armonía organiza- } \\
\text { cional, ¿Cuáles considera prioritarios? ¿Cuáles considera mediables en } \\
\text { un conflicto? }\end{array}$ \\
\hline & ¿Considera que estas condiciones son mediables? ¿De qué manera? \\
\hline & $\begin{array}{l}\text { ¿Qué efecto tendría la mediación de estas condiciones en el empode- } \\
\text { ramiento del sujeto? }\end{array}$ \\
\hline & $\begin{array}{l}\text { ¿Qué efecto tendría la mediación de estas condiciones en la armonía } \\
\text { organizacional? }\end{array}$ \\
\hline Unidad de Análisis & Preguntas Entrevista Grupo B \\
\hline \multirow{3}{*}{$\begin{array}{l}\text { Mediación } \\
\text { Organizacional }\end{array}$} & ¿Considera que estas condiciones son mediables? ¿De qué manera? \\
\hline & $\begin{array}{l}\text { ¿Qué efecto tendría la mediación de estas condiciones en el empode- } \\
\text { ramiento del sujeto? }\end{array}$ \\
\hline & $\begin{array}{l}\text { ¿Qué efecto tendría la mediación de estas condiciones en la armonía } \\
\text { organizacional? }\end{array}$ \\
\hline
\end{tabular}


Lo Inicuo en las Organizaciones
¿Cuáles considera son las condiciones inequitativas y/o injustas en el sitio de trabajo?

¿Cree usted que las personas se acostumbran a estas condiciones?

¿Cómo cree usted que afecta a las personas acostumbrarse a estas condiciones?

Fuente: Elaboración propia.

\section{RESULTADOS}

Las entrevistas definitivas se aplicaron de manera presencial en las ciudades colombianas de Bogotá, Barranquilla y Neiva, y otras vía Zoom con profesionales laboralmente activos en las ciudades de Medellín, Cali y Leticia. Cada entrevista tuvo una duración que osciló entre los 40 y 120 minutos.

\section{Respuestas anidadas por categoría de análisis}

Al examinar el compendio textual de las entrevistas, se organizó el contenido central de cada una de ellas, en un sistema de categorías de análisis ya predeterminado por el estudio; los patrones significativos al interior del discurso fueron determinantes para vincular las respuestas con las categorías, tal como se puede observar a continuación:

\section{Tabla 5. Respuestas anidadas por cafegoría de análisis}

\begin{tabular}{|c|c|}
\hline 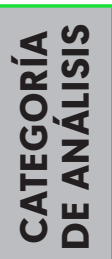 & RESPUESTAS \\
\hline \multirow{7}{*}{ 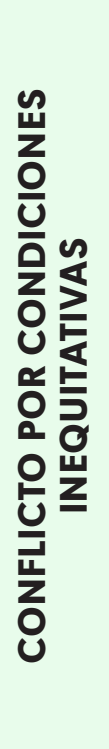 } & Claro, porque los celos hacen que las personas no se comuniquen, o se traten seco. \\
\hline & $\begin{array}{l}\text { Siempre, son muchas las personas que no saben disimular, y no se concentran en su trabajo, por } \\
\text { estar viendo el trato preferencial que le dan a otro. }\end{array}$ \\
\hline & $\begin{array}{l}\text { A veces no llega ni a ser conflicto, es como un malestar, la gente se queda como amargada, triste } \\
\text { y eso afecta no sólo las relaciones sino también el trabajo en sí que hace. }\end{array}$ \\
\hline & $\begin{array}{l}\mathrm{Si} \text {, y afecta mucho el clima laboral, porque los trabajadores prefieren dejar de comunicarse, y eso } \\
\text { afecta los procesos. }\end{array}$ \\
\hline & $\begin{array}{l}\text { Se ve mucho cuando las personas sienten que hacen más y mejor las cosas que otros, entonces } \\
\text { pueden dejar de esforzarse. }\end{array}$ \\
\hline & $\begin{array}{l}\text { Yo recuerdo que había una muy buena trabajadora, y era muy callada, un día cualquiera se fue y } \\
\text { dijo que en la empresa le iba mejor a los que no hacían nada, que estaba cansada de eso. }\end{array}$ \\
\hline & Más que conflicto o problemas de frente, se presentan chismes y comentarios que dañan el clima. \\
\hline
\end{tabular}




\begin{tabular}{|c|c|}
\hline \multirow{7}{*}{ 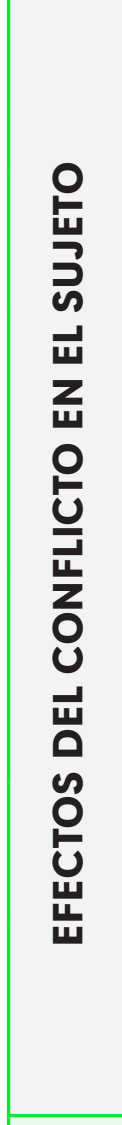 } & $\begin{array}{l}\text { Afectaría en su área laboral ya que no se desempeñaría de la misma manera que en } \\
\text { una condición justa, en un buen clima, perdiendo así el interés por realizar un excelente } \\
\text { trabajo y comenzar a tomar una posición silenciosa y menos activa. }\end{array}$ \\
\hline & $\begin{array}{l}\text { En su manejo emocional o falta de amor propio, bajo rendimiento laboral, falta de com- } \\
\text { promiso, reproceso en los trabajos. }\end{array}$ \\
\hline & $\begin{array}{l}\text { Las condiciones injustas e inequitativas en el trabajo afectan tanto la parte productiva, } \\
\text { como la emocional del trabajador, al tener condiciones inferiores a otros compañeros de } \\
\text { trabajo, su producción o eficiencia se va a ver disminuida frente a estos y emocionalmente } \\
\text { sentirá que su trabajo no es valorado y que no es importante para la organización. }\end{array}$ \\
\hline & $\begin{array}{l}\text { Afecta el clima laboral, incluso a personas que no tienen que ver con el conflicto, pero } \\
\text { que lo presencian o perciben el mal ambiente, se estresan y se distraen de sus funciones. }\end{array}$ \\
\hline & Inseguridad, falta de confianza en el otro y en él mismo. \\
\hline & $\begin{array}{l}\text { Hay gente que se enferma, yo conozco personas que les da migraña, náuseas, les afecta } \\
\text { el sueño y así. }\end{array}$ \\
\hline & $\begin{array}{l}\text { El conflicto es parte de la vida, pero si no se maneja bien, daña a las personas, en espe- } \\
\text { cial cuando no miden sus palabras o actos, actúan con las emociones y después no miden } \\
\text { las consecuencias. }\end{array}$ \\
\hline \multirow{2}{*}{ 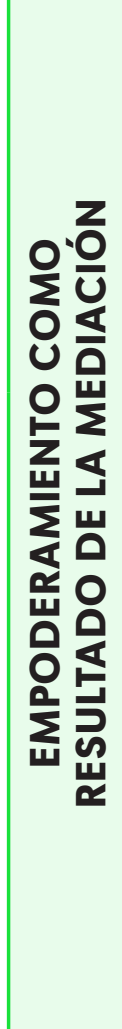 } & $\begin{array}{l}\text { Mediación como tal no, usualmente cuando hablamos del empoderamiento es el famosí- } \\
\text { simo mito laboral, que venga lo empodero a usted del cargo de contador, si el contador } \\
\text { empodera al auxiliar contable y en últimas el auxiliar contable hace todo el trabajo y el } \\
\text { contador firma y le entrega al jefe ya el documento, entonces el ejercicio fue muy bien } \\
\text { hecho y somos todos empoderados y cada cual se empodera de su función la realidad es } \\
\text { que en últimas lo que están haciendo es un desplazamiento de funciones prácticamente } \\
\text { al subordinado o al eslabón más débil de la cadena. }\end{array}$ \\
\hline & $\begin{array}{l}\text { El verdadero empoderamiento es hacer un correcto entrenamiento en trabajo en equipo } \\
\text { para que en verdad ellos sientan que lo que están haciendo hace parte de algo que en } \\
\text { verdad se empoderen mediar para que sepan que su aporte va hacia algo que están } \\
\text { construyendo en común no solamente todo el mundo habla de una meta, y le asignan a } \\
\text { usted un pedacito para que usted lo haga y haga su meta y ¿dónde está el resto? enton- } \\
\text { ces es aquí donde uno ve las diferentes estructuras muy bonitas a nivel organizacional ya } \\
\text { sean piramidales como las quieran identificar pero la realidad es que cada cual aporta } \\
\text { lo suyo y nadie se entiende con nadie entonces el empoderamiento se queda corto y deja } \\
\text { de ser un trabajo en equipo y se convierte el típico trabajo en grupo que hacíamos en el } \\
\text { colegio, cada cual hace su parte, entrega y ahí quedamos, no nos preocupamos ninguno } \\
\text { uno por el otro sino solamente por el resultado o la meta. }\end{array}$ \\
\hline
\end{tabular}


Efectivamente el empoderamiento es un elemento de la armonía organizacional que se puede mediar, cada miembro de la empresa o entidad debe empoderarse de su lugar de trabajo y las funciones que realiza, esto es desarrollar eficientemente sus funciones o tareas en beneficio de la empresa esta refleja el sentido de pertenencia del trabajador hacia ésta.

Cuando hablamos de empoderamiento hablaríamos también de límites, los límites dentro de lo que las funciones del empleado y las funciones del empleador, eso se aclara con la mediación; o sea habría que delimitar para que no haya una sobrecarga en el empleado.

Sí, porque la mediación aporta directamente valor al talento humano de la organización y con las personas se logra la armonía con las partes interesadas de la compañía.

Se puede decir que sí a la mediación. Qué sucede con el empoderamiento en muchas oportunidades, solamente lo enfocan al tema de los jefes, que los jefes tienen que empoderar a sus subalternos y lo único que hacen es delegar sus responsabilidades más nunca se maneja un empoderamiento real o se les da una guía o un entrenamiento o un acompañamiento para que en verdad desarrollen esta habilidad.

Si claro al tu poder tener pues cierta autonomía cierta independencia la facilidad de poder asumir responsabilidades que no tengas tu que estar siempre dependiendo de alguien más, sino que tu tengas como cierta área de libertad en lo que haces es importante, y generalmente eso se medía con los jefes.

Este año que se hizo una mediación muy importante desde que haya apoyo real de los directivos de la organización, que, si los directivos no les interesa, por más ejercicio que se haga no hay por dónde hacer el cambio. No hay por dónde hacer mediación; entonces en ese sentido, en esa experiencia yo medie frente a los directivos, los grandes de la organización, mi principal barrera era la directiva que tenía cercana o sea la jefa directa. Considero que la mediación es responsabilidad uno de los elementos porque al dejar responsabilidad a las empresas, y tengan una mayor satisfacción por su trabajo fomentado su compromiso y asumen una cultura positiva al realizar sus funciones, pero se necesitan muchos más elementos para llegar a la armonía organizacional.

Sin lugar a duda las condiciones inequitativas son mediables, pero el actor principal para lograrlo es el mismo trabajador, puesto que es él que conoce su labor, las herramientas y condiciones ambientales que necesita para desempeñar eficientemente su labor, logrando el máximo nivel de rendimiento, si éste justifica correctamente la necesidad de reducir estas inequidades para el bien de la organización puede ser escuchado por sus superiores y lograr ese objetivo. 
Mediable el manejo de comunicaciones trasversales y Socialización de objetivos organizacionales y plan estratégico. Mediables en un conflicto: Reuniones efectivas y Designación de responsabilidades.

Mediable la capacitación, Manejo de comunicaciones trasversales, Designación de responsabilidades, Evaluaciones de desempeño, Reuniones efectivas, Compensación salarial, Socialización de objetivos organizacionales y plan estratégico, Rendición de cuentas.

Mediables los conflictos en general, mediante el diálogo a través de un grupo interdisciplinario.

Para mí todos los elementos de la armonía que se median, son importantes. Aunque consideró fundamentales a la Responsabilidad, Equidad y Respeto.

Mediar la Gestión de la diversidad. Comunicación recíproca. Fomentar valores como el respeto, tolerancia, trabajo en equipo, etc. Igualdad de condiciones.

Considero qué si son mediables, principalmente por medio del diálogo, de no ser así existen normas y reglas que solventan este tipo de situaciones.

El conflicto es consustancial a la vida de las personas, entonces no hay que tenerle miedo, hay que tenerle miedo a la forma como se soluciona, para eso es la mediación.

Es difícil mediar porque la empresa tenía una junta directiva nacional, unos jefes nacionales y unos gerentes de sucursales, yo respondía directamente a los jefes nacionales, les informaba todas las situaciones, había un canal para anuncios de acoso laboral pero aquí entra a influir otro factor que es el tema de los amiguismos, el tema de los beneficios de compañeros cercanos, entonces la encargada de manejar los problemas de acoso laboral era muy amiga de la gerente de la sucursal por consiguiente todas las denuncias de acoso laboral no escalaban, se quedaban ahí.

Difícilmente mediar, difícilmente porque volvemos a lo mismo, estamos con unos temas de amiguismos en unos temas de influencias externas que no nos permiten obtener un buen resultado, lo viví en carne propia e incluso en el cambio laboral que tuve, actualmente también se presentó mucho, hay compañeros que su rendimiento laboral no era el mejor y lastimosamente salimos personas que no tuvimos llamadas de atención observaciones e incluso obtuvimos reconocimientos pero lastimosamente no tenemos el amigo político, el que nos colabore, la gente que nos ayude a estar ahí entonces son situaciones muy difíciles. 


\begin{tabular}{|c|c|}
\hline \multirow{3}{*}{ 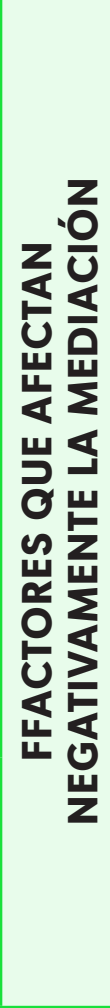 } & $\begin{array}{l}\text { Yo creo que no se puede mediar en el contexto organizacional, o sea no, hay condiciones } \\
\text { que tú, o sea por eso el salario tú lo medias y dices bueno yo puedo he trabajado más } \\
\text { por menos salario, pero eso me implica que tengo menos horas laborales o que tengo } \\
\text { bueno salario, pero me dan medicina prepagada pero el bienestar como tal lo que hace } \\
\text { es que te arraigues, o sea que tú sientas como ese interés y esa pertenencia, venga me } \\
\text { valoran, venga aquí me dan otras cosas o aquí me tienen en cuenta para otras cosas } \\
\text { entonces digamos que este tema de bienestar si es importante tenerlo sólido para que el } \\
\text { empleado tenga más pertenencia a la empresa, eso sí no se negocia. }\end{array}$ \\
\hline & $\begin{array}{l}\text { Mediables... en explotación, es una forma de violentar a alguien, como vas a mediar } \\
\text { con la violencia, es hacerle daño al otro; yo diría no mediable, diría que más bien es un } \\
\text { síntoma de que hay algo que hay que modificar y que hay que modificarlo ahora, porque } \\
\text { justo ahora es donde más se están presentado estos casos, o tal vez sólo hasta ahora les } \\
\text { estamos poniendo atención. }\end{array}$ \\
\hline & $\begin{array}{l}\text { Pueden mediar esos conciliadores que han sido elegidos por las asambleas, por la co- } \\
\text { munidad, como no saben bien su función entonces es el último que eligen con cualquie- } \\
\text { ra que pase, por eso te quiero contar que por eso hay muchos que no han solucionado } \\
\text { conflictos. }\end{array}$ \\
\hline 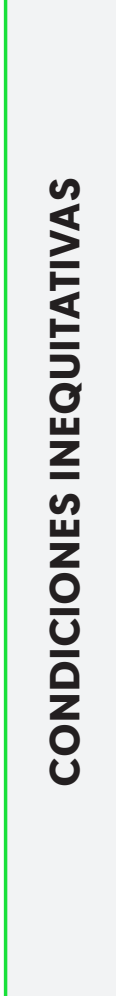 & $\begin{array}{l}\text { Bastante } 100 \% \text { dentro de una experiencia que yo tuve en el año } 2012 \text { en una empresa } \\
\text { nacional yo respondía a la sede central no respondía a la sucursal, el problema era que } \\
\text { era la mejor a nivel nacional en consecución de metas pero a nivel de clima era la peor, } \\
\text { por qué se presentaba, por lo que te estaba comentando; a la jefe sólo le importaban sus } \\
\text { metas y no le importaba su equipo de talento humano simplemente éramos unos robots } \\
\text { trabajando y no les importaba que trabajaran } 12 \text { horas y siguieran trabajando desde su } \\
\text { casa, no les importaba que ellos siguieran sin almuerzo, sin desayuno o trabajáramos } \\
\text { fines de semana, entonces cuando se empezó un proceso real de mediación con la sede } \\
\text { nacional se generaron diferentes conflictos... que era el coordinador de talento humano } \\
\text { en dicha oportunidad donde se buscó reestablecer los derechos, las compensaciones de } \\
\text { las horas porque ellos no pagaban horas extras, pero si se buscaba la compensación de } \\
\text { las horas para que las personas pudieran disfrutar que se cumplieran los acuerdos y se } \\
\text { hizo un ejercicio muy importante durante un año que generó bastante recordación porque } \\
\text { el mismo talento se dio cuenta que era algo necesario pero al retirarme de la compañía } \\
\text { precisamente por el múltiple acoso al que estaba siendo sometido por parte de esa ge- } \\
\text { rencia, todo el proceso se cayó porque se volvió a generar un proceso de imposición no } \\
\text { de negociación, no de diálogo y lastimosamente lo que muchas empresas buscan es una } \\
\text { meta sin importar de que forma la consiguen. }\end{array}$ \\
\hline
\end{tabular}


Lastimosamente son esas empresas que se van adaptando a la moda, una empresa que era mutual ahora es una S.A.S porque son formas de proteger los... Financieros. Los intereses de los diferentes accionistas entonces anteriormente se llamaba profesional de gestión del talento humano nivel 3, tengo entendido que ahora se llama coordinador de sede talento humano y cada momento van dependiendo de la moda o del estudio que haga el líder de talento humano a nivel nacional va modificando la estructura orgánica, se van más enfocados al tema de resultados, vuelvo y lo menciono nuevamente.

Un tema en verdad de talento humano puesto que existen varias áreas peor a la final ninguna vela por la protección real de los colaboradores.

Las decisiones que yo tomaba debían ser abaladas por la gerencia de la sucursal y como se presentaban ciertas diferencias de pensamiento no las consideraba y a veces no las avalaba hasta el punto, como algo tan sencillo, un programa de vacaciones que se les podía dar a voluntad a los colaboradores dependiendo de que tanto les agradaba la persona se les autorizaba o no se les autorizaban las vacaciones a pesar de que ya hubieran cumplido el tiempo o sencillamente llevaran 2 o 3 períodos acumulados.

Situaciones injustas, la mala distribución, no digo que por desconocimiento porque todos conocen muy bien su organización. La mala distribución en la carga laboral puesto que vayámonos a algo tan sencillo un tema jurídico, manejamos dos abogados un caso donde se involucran 100 millones de pesos y 10 casos en que se involucran 10 millones de pesos entonces no pues es el mismo tope, pero la realidad es que el de 100 millones de pesos simplemente es ir a dejar un documento erradicarlo y hacer el debido proceso y termina; el de los 10 millones de pesos toca empezar a recaudar, ubicar las personas, empezar las demandas, las negociaciones, las concertaciones y demás. Entonces es donde yo te menciono que se sobrecarga a unos y a otros simplemente se le entrega, a pesar de que puede ser la misma meta, recaudar un dinero el volumen es diferente, mientras el uno atiende un caso el otro está atendiendo 10, eso es un tema de sobrecarga laboral.

Otro de los grandes factores es lo que nosotros conocemos como "hora silla" o vulgarmente le dicen "hora nalga" que es estar de 8 de la mañana a 11, así estén tomando tinto, se estén viendo la cara y en verdad no se mida la productividad o el cumplimiento de las metas reales que se pueden generar; incluso una media jornada y la otra media jornada se puede utilizar para otros factores. Otro de los factores es el tema de no hacer una correcta selección de personal para cualquier cargo que sea que pues vuelve a incluir el tema del amiguismo métame a este amigo que nos puede colaborar, nos puede servir, colabóreme es tal vez una persona que no sabe y pues lo que nos genera es sobrecarga laboral sobre los que sí están haciendo; consideraría yo que son como los principales. 





Por la necesidad laboral sí. Hay gente que se mantiene allí por una necesidad económica, por una estabilidad, entonces las personas se acostumbran, se vuelven sumisas a la situación y lo que hacen es mantenerse, y ya generan una desesperanza aprendida sobre el tema para no poder generar ninguna afectación incluso algunos ya lo que hacen es llevar lo dirían nuestros abuelos un propio calvario interno lo que nosotros ya conocemos como una... para poder llevar la situación hasta donde más se puedan aguantar.

Pues cuando ya la situación se vuelve como tan reiterativa si o sea ya se adaptan o sea ? ya que como que bueno pasó y así va a ser y esto no va a cambiar y así tú digas no se hace nada entonces ya la gente como que lo entiende como normal y ya. Yo creo que es más por el tema como de, "estabilidad”, o sea yo pienso que bueno hay un tema de personalidad que hay gente que finalmente tiene esa necesidad de buscar, de explorar, de hacer esas cosas, son como más activos no, así estén bien en las empresas así tengan muchas cosas buenas o les estén ofreciendo todo de pronto ellas están buscando algo más y salen y se van, pero los que son así como más digamos estables o esas personas que se quedan a pesar de yo creo que es una de o tu sientes finalmente no tienes para donde agarrar o te quedaste porque o sea no hubo más que hacer o tal vez consciente o inconscientemente están esperando a que en algún momento algo llegue a ser el cambio pero generalmente es por eso, porque, tal vez ya se adaptaron, ya se acostumbraron a eso y ya salir a buscar ya salir hacer otras cosas ya también como que los desestabiliza como que los saca de esa zona de confort y también como que puede ser otro impacto más duro que en lugar de ir y buscar y de pronto que no sabe con qué se va a encontrar ahí atrás, además que la cultura siempre ha sido así eso no va a cambiar las cosas son así y entonces ya se mentalizan y ahí quedan.

Creo que hay personas que se acostumbran a estas injusticias por miedo o temor de perder su trabajo y esto creo que lo hacen por su necesidad y su personalidad sumisa, en cambio las personas que ya tienen un poco más de estudio y menos necesidades no se acostumbran a estas situaciones.

Se podrían acostumbrar en caso de que esta persona tenga necesidades financieras y tenga que someterse para continuar laborando o también porque tenga experiencias anteriores donde las injusticias pudieran ser peores.

Pero no tiene el estatus o el reconocimiento social que tiene si trabajó como notario en la rama judicial, ya, aunque pueden ganar lo mismo podríamos decir en algún momento, no tiene el mismo reconocimiento y estatus, entonces la persona prefiere seguir dentro del modelo cultural tratando de mantenerse dentro de lo que es socialmente aceptado, hasta que ya llega el momento en que no da más, se quiebra, se afecta y acá lo tenemos en el área de salud. 
Tiene que ver con cuestiones culturales también, nos han enseñado de que sólo en la medida de que seamos productivos, somos personas valiosas y además de que esa productividad tiene que ver con un sueldo, un estatus que se lo da el cargo o el lugar de trabajo; es decir, si yo trabajo como músico en la calle, es un trabajo también.

Qué sucede con ellos, actualmente pues yo me desarrollo como asesor en riesgos laborales y es muy común es muy frecuente la aparición de patologías que el DCM4, DCM5

- ya, nos ha ido ampliando por eso incluso, en el año 2017, 2014 perdón se generó la nueva tabla de enfermedades laborales donde ya se amplió anteriormente teníamos como 7 no más.

Pues mucho, o sea porque es que tú siempre, tu como persona cuando sientes que te están de alguna manera como vulnerando pues puede haber gente que no dice nada, puede haber gente que pelea, puede haber gente que finalmente dice no pues en algún momento me tengo que ir, pero finalmente eso impacta en el desempeño, eso impacta en como tú te proyectas con la gente, eso impacta en el ambiente, si o sea como tú estás o como tú te sientas es lo que reflejas con las personas que trabajas es como si la percepción cambia y por lo menos tú ves al empleado que está molesto, que está casado, que se queja de todo que de pronto siempre ha buscado o por lo menos que yo he sido siempre la psicóloga en la empresa y no hay para donde más arrancar, sí, pero sí tú dices, no acá pues me reconocen o yo acá puedo estudiar o acá yo tengo las posibilidades o hay oportunidades para mí bueno, todas esas cosas ayudan, pero tu sientes que estás estancado y que tu propones y nada, no te escuchan como que ya llegas a un punto en el que te estancas, te quedas ahí y lo único que haces es quejarte, bueno, en fin, hay gente que hasta se enferma por ese tipo de situaciones entonces es bien complejo.

Pues, yo en particular tengo un caso, o tuve un caso porque ya no trabaja conmigo pero él era o es porque él todavía trabaja en la empresa él es jefe de mantenimiento y él como tal es su perfil es súper excelente en particular, pero ya como que llegó un punto en el que la empresa no le daba más y el por su familia por sus hijas, la estabilidad se quedó ahí; él vive amargado, se queja todo el tiempo y eso por lo menos el sufre de migrañas, sufre de gastritis, estrés crónico, él vive así vuelto nada o sea ya como que finalmente todo síntoma, se sintomatizó y el terminó con una gastritis tenaz, o sea eso fue lo que yo terminé viendo en él o sea pues igual él tuvo oportunidades, él tuvo como salir, pero siempre, como te decía ahorita, "ay no pues si me voy a Bogotá entonces las niñas, ya me voy para Bogotá entonces mi mujer, no, no esperemos a que llegue mi jefe, aquí cambian las cosas, o no esperemos para la próxima cuando llegue otro equipo", entonces se quedó esperando a ver cuándo y ahí se quedó. 
De hecho, él tuvo un problema... él comenzó por la gastritis y ahí tuvo un problema porque a lo último que supe porque mi marido trabaja con él, fue un tema como de, o sea a él le tocó dejar hasta ciertas comidas porque ya estaba en la mala yo le decía es un hombre sano es un hombre tranquilo, o sea, digamos que cuando tú lo ves normalmente se ve re tranquilo o sea tú lo ves bien y dices chévere, él lo hace, pero el terminó enfermándose así.

Yo creo que justamente por eso ocurre la enfermedad mental, porque la persona no logra adaptarse, les toca quedarse y se enferman, no creo que se acostumbren, cada persona expresa la enfermedad de manera distinta algunos desde la parte mental, otros desde la parte física, acá he tenido también pacientes que muestran accidentes de trabajo con lecciones físicas muy graves y a consecuencia de eso alteraciones cognitivas y que de base está la sobrecarga laboral y el mal ambiente laboral, las condiciones inadecuadas del trabajo.

Comienzan con dolores físicos, dolores de cabeza frecuentes y constantes, comienzan a tener alteraciones gástricas e intestinales, palpitaciones, tienen la sensación de que les palpita cierta área del cuerpo, el ojo, la pierna, la mano; dolencias típicas del exceso de trabajo acumulado, la alteración del túnel del Carpo, manguito rotador del hombro, daños o dolores en la zona lumbar en la zona cervical, después empiezan a tener sensaciones de adormecimiento de algunas partes del cuerpo, sensación de entumecimiento, sensaciones de ataques de pánico en donde la persona siente en el espacio laboral que se ahoga que siente que ya no puede resistir más esa sensación, llegan a estados de depresión, ansiedad intensa, y luego comienzan a generarse otras como pérdidas de memoria, dificultad en la concentración, se desorientan en espacio tiempo, luego encontramos, tuve un caso muy particular, son muy pocos, en que la persona se pierde, se desorienta y no llega a reconocer incluso a su familia o incluso estados de convulsión, que serían como un estado de convulsión psicótica que sin tener antecedentes de epilepsia, o tener algún daño cerebral específico, pueden llegar a tener ese tipo de situaciones, estos casos son extremos, se han presentado muy pocos pero la unión de todos estos factores entre factores de personalidad, sobre carga en el trabajo y hay que tener en cuenta otra cosa, tiene mucho que ver la influencia del género, las mujeres están más sobrecargadas por tener también la función del hogar, actualmente, afortunadamente se está equiparando un poco más esa función y el hombre está participando mucho más en las labores del hogar, haciéndose consciente de que también corresponde a todo aquel que vive en casa, entonces ayuda un poco, pero se está sobrecargando mucho la función de la mujer, entonces no solamente tiene que salir a trabajar, rendir como empresaria, como empleada de una multinacional en $x$ caso, sino que demás tiene que llegar a casa a ocuparse de los quehaceres del hogar y a seguir trabajando lo que no logró terminar en la oficina.

Fuente: Elaboración propia. 
Este proceso de anidación de respuestas se realizó de manera manual, para luego correr la información en el software NVivo, como se muestra a continuación.

\section{Resultados Directos por Unidad y Cate- goría de Análisis}

El abordaje de las respuestas obtenidas durante la entrevista comprendió un análisis sistemático de palabras y frases clave, de manera componencial y taxonómica (Hernández \& Tamez, 2014); esta dinámica se realizó mediante el Software Maxqda para delimitar códigos clave, jerarquizarlos y de- terminar su relación con el tema central de estudio Mediación de lo Inicuo.

\section{Unidad de Análisis Mediación Organiza- cional}

En la categoría "factores que afectan negativamente la mediación" se destacaron códigos alusivos a los flujos de poder organizacionales tales como "confusión en los niveles de autoridad", "desequilibrio salarial", "intereses particulares" y "falta de pertenencia", así como códigos relacionados directamente a la mediación como el "desconocimiento de la mediación" y "temor al conflicto".

\section{Gráfico 1. Categoría de Análisis Factores que Afectan Negativamente la Mediación}



Fuente: Elaboración propia.

Por su parte, la categoría de análisis "empoderamiento como resultado de la mediación", destacó códigos vinculantes propios del mundo de las organizaciones como "ta- lento humano", "liderazgo idóneo" y "aporte personal", y algunos alusivos directamente al ejercicio de la mediación como "mediación de la armonía" y "logro de la armonía". 


\section{Gráfico 2. Categoría de Análisis Empoderamiento}

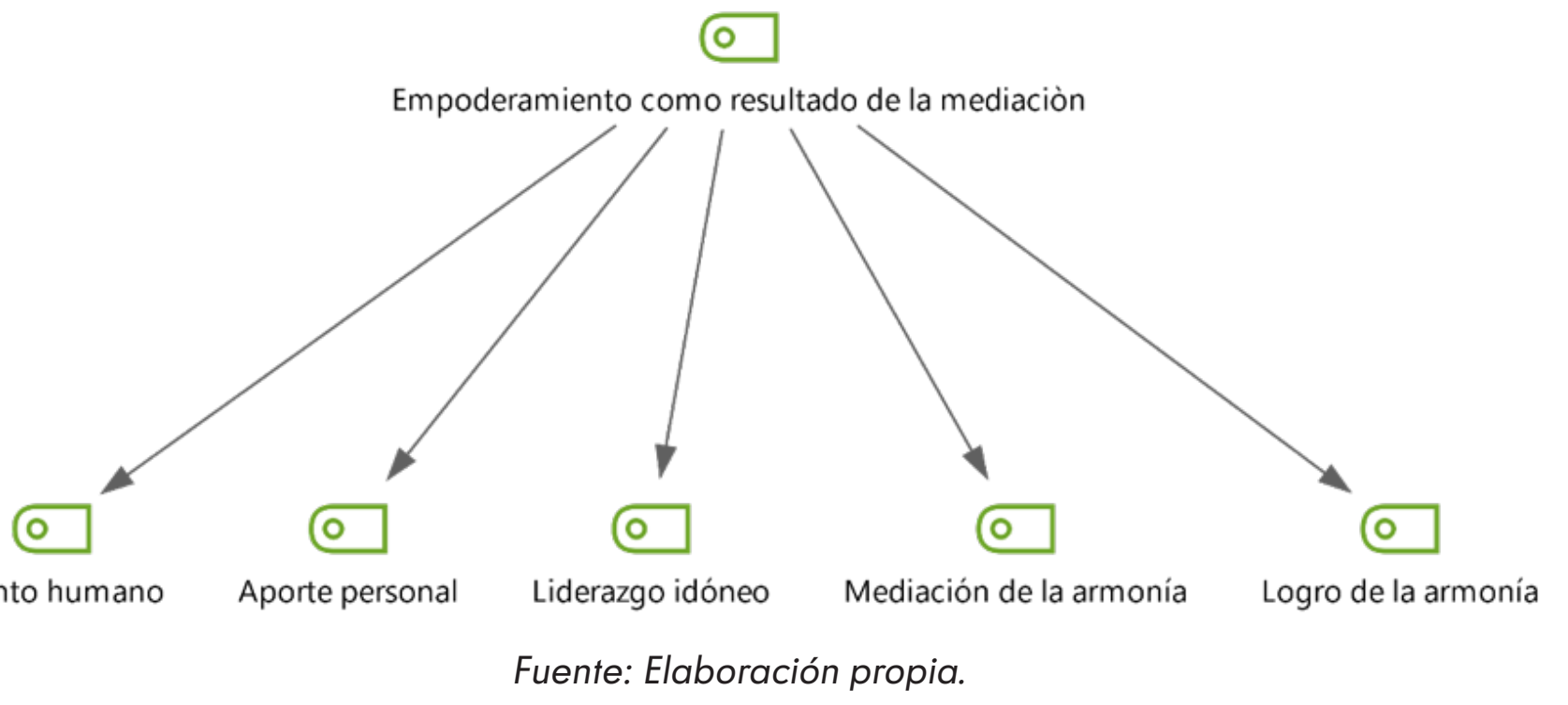

En la categoría de análisis "elementos para el logro de la armonía", se destacaron los siguientes códigos:

\section{Gráfico 3. Categoría de Análisis Elementos para el Logro de la Armonía}

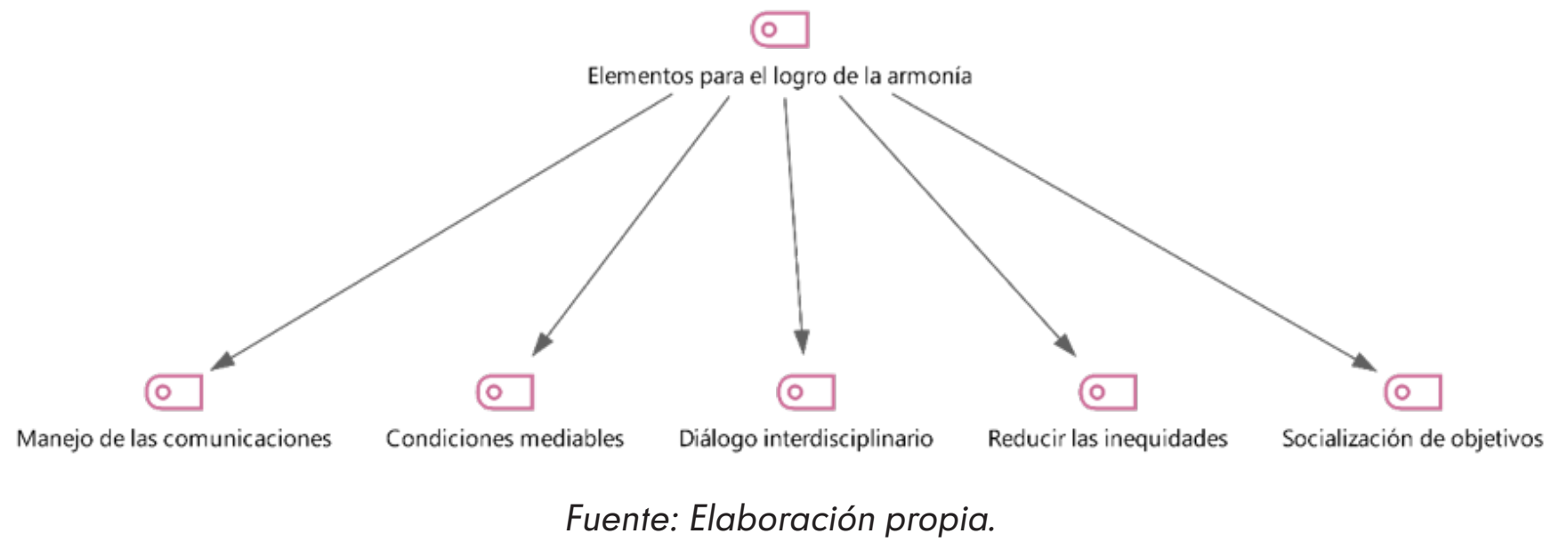

\section{Unidad de Análisis Nafuralización de lo Inicuo}

En la categoría "condiciones inequitativas" se destacaron los siguientes códigos: 


\section{Grafico 4. Categoría de Análisis Condiciones Inequitativas}

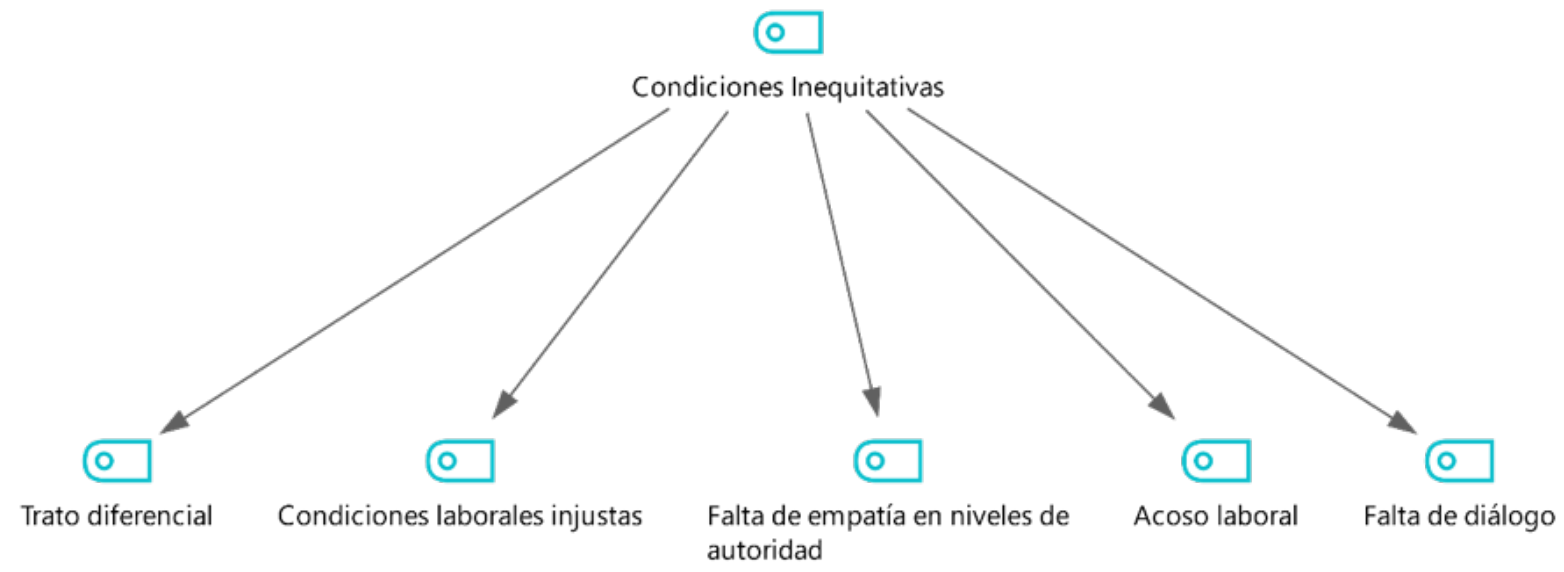

Fuente: Elaboración propia.

Por su parte, en la categoría "Facultad de tabilidad laboral", de manera particular acostumbrarse a las condiciones inequi- sorprende encontrar la palabra "resiliencia" tativas", se pusieron en contexto códigos como un código destacado, posiblemente comúnmente asociados a la realidad del para hacer alusión a una posición menos famercado laboral de Colombia como "incer- talista y más proactiva frente a la realidad tidumbre sobre el cambio", "necesidades de adaptarse a lo inicuo. personales", "apatía en el trabajo" e "ines-

\section{Gráfico 5. Categoría de Análisis}

\section{Facultad de Acostumbrarse a las Condiciones Inequitativas}

\section{○}

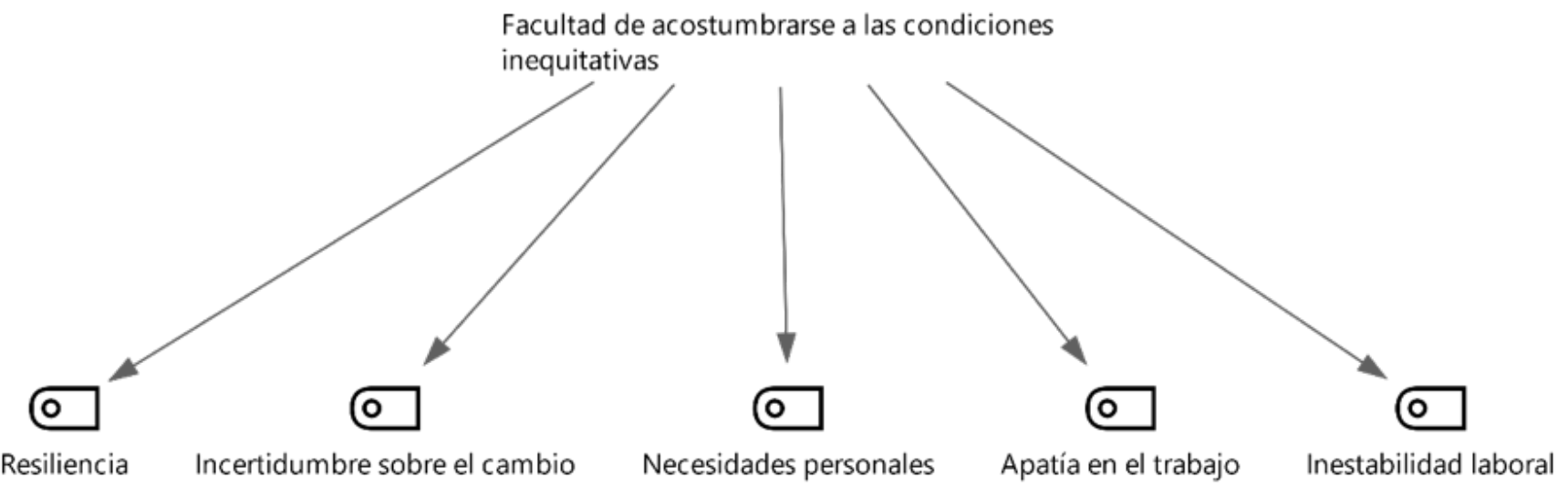

Fuente: Elaboración propia. 
Finalmente, en la categoría "efectos en el sujeto de acostumbrarse a lo inequitativo", se destacan algunos códigos que merecen una lectura más detallada como "arraigo cultural", "riesgos laborales" y "ambiente de trabajo", al tener la facultad de gene- rar un gran impacto en el mundo de las organizaciones, de igual manera los códigos "frustración personal" y "enfermedad mental" alertan sobre los efectos en la salud del sujeto en razón a acostumbrase a lo inicuo.

\section{Gráfico 6. Categoría de Análisis Efectos en el Sujeto de Acostumbrarse a lo Inequitativo}

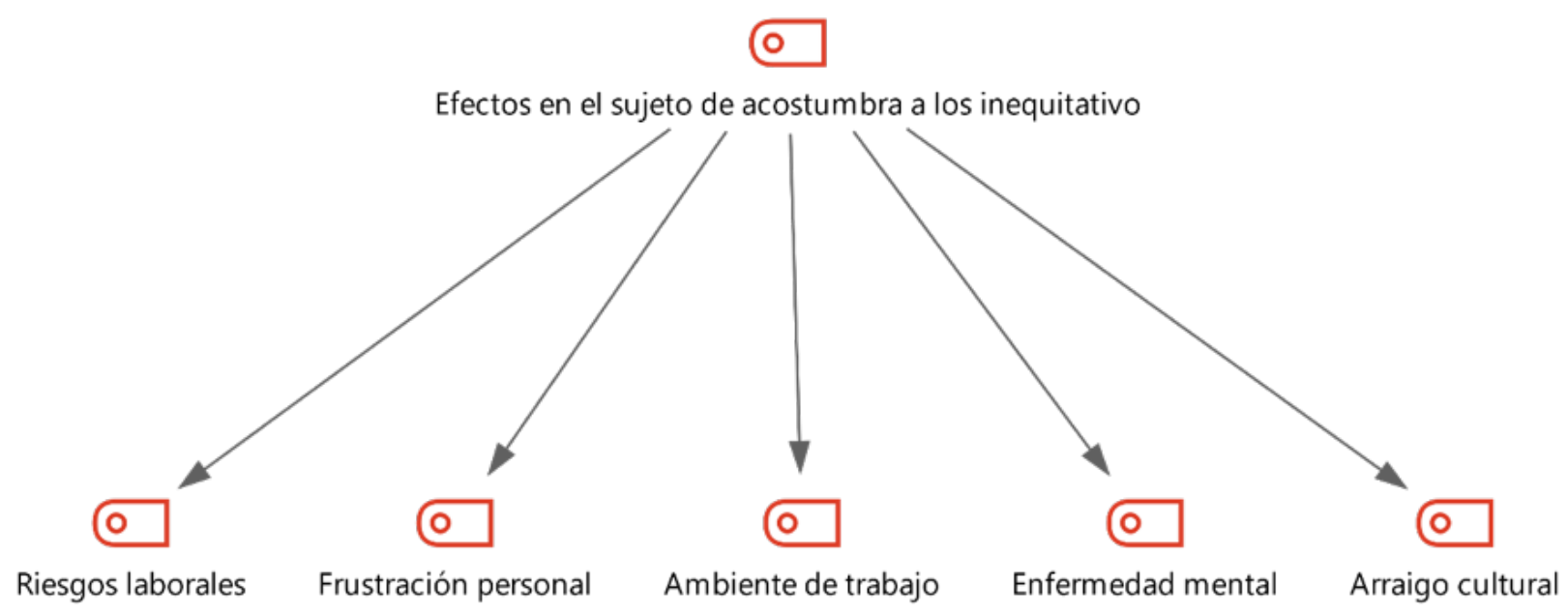

Fuente: Elaboración propia.

Unidad de Análisis Conflicto Laboral Interpersonal

En la categoría "Conflicto por condiciones inequitativas" se destacaron algunos códigos alusivos a su génesis como "falta de co-

\section{Gráfico 7. Categoría de Análisis Conflicto por Condiciones Inequitativas}



municación", "liderazgo inefectivo", "conflictos interpersonales" y "trato desigual", y otros en referencia a las consecuencias como "clima laboral" y "estado anímico". 
Por su parte, en la categoría "efectos del conflicto en el sujeto", se destacan los siguientes códigos:

\section{Gráfico 8. Categoría de Análisis Efectos del Conflicto en el Sujeto}

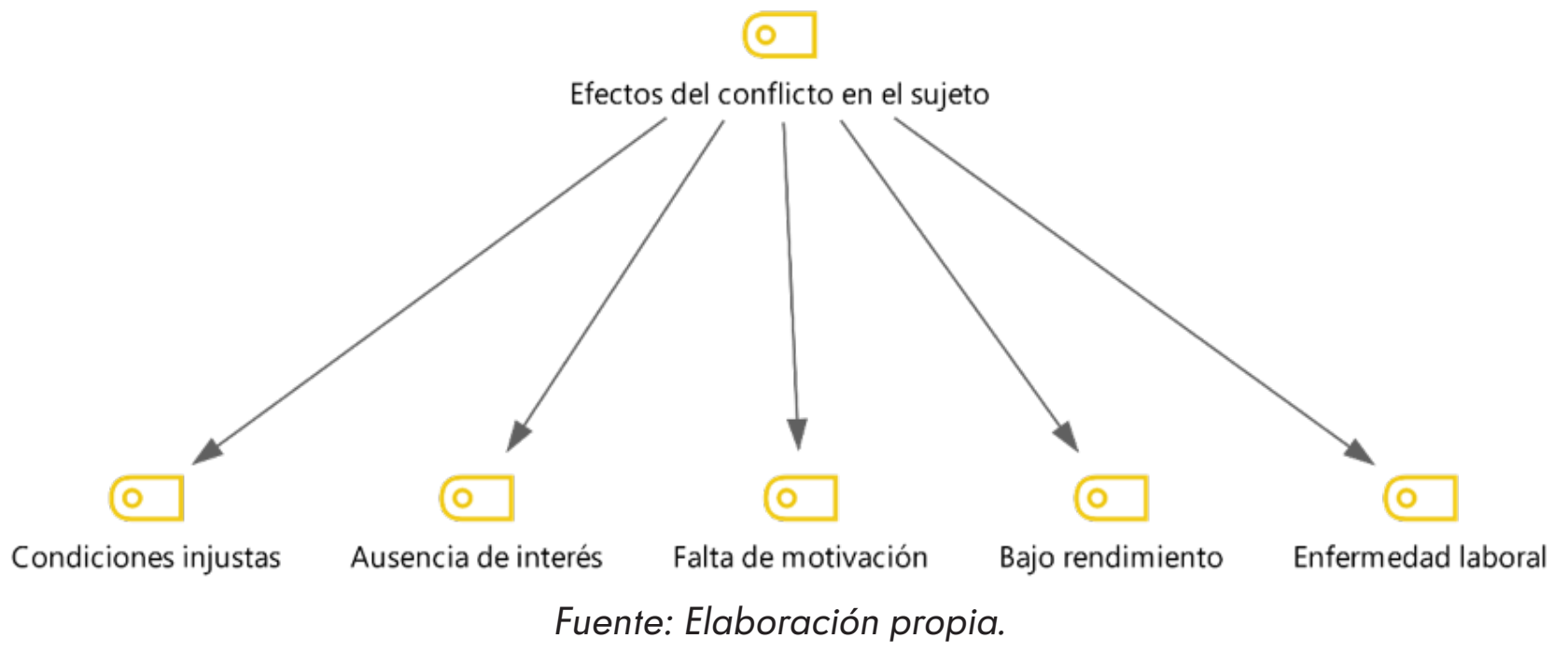

Finalmente, la codificación interactiva provee una nutrida información de códigos vinculantes a manera de Red en Globo y Nube de Palabras, a saber:

\section{Gráfico 9. Red de Códigos en Globo}

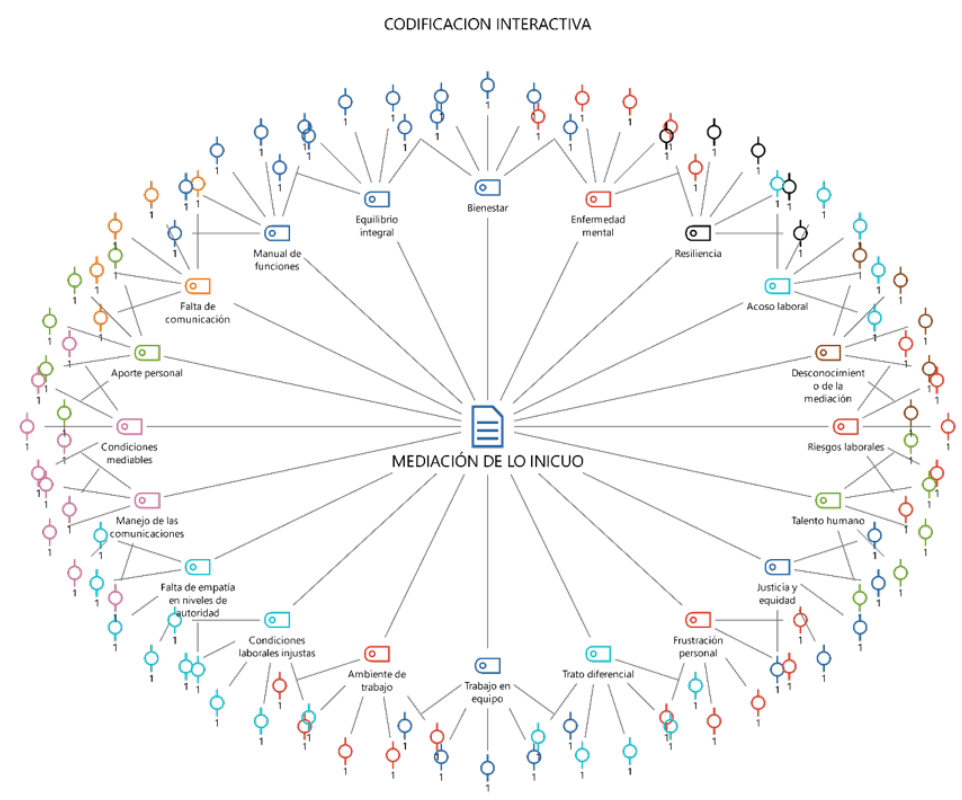

Fuente: Elaboración propia. 
Este gráfico vincula todos los códigos asociados a la investigación, y muestra de manera global todos los factores que influyen de manera positiva y negativa en la mediación de las condiciones laborales inicuas.

\section{Gráfico 10. Nube de Palabras de Códigos Vinculantes}

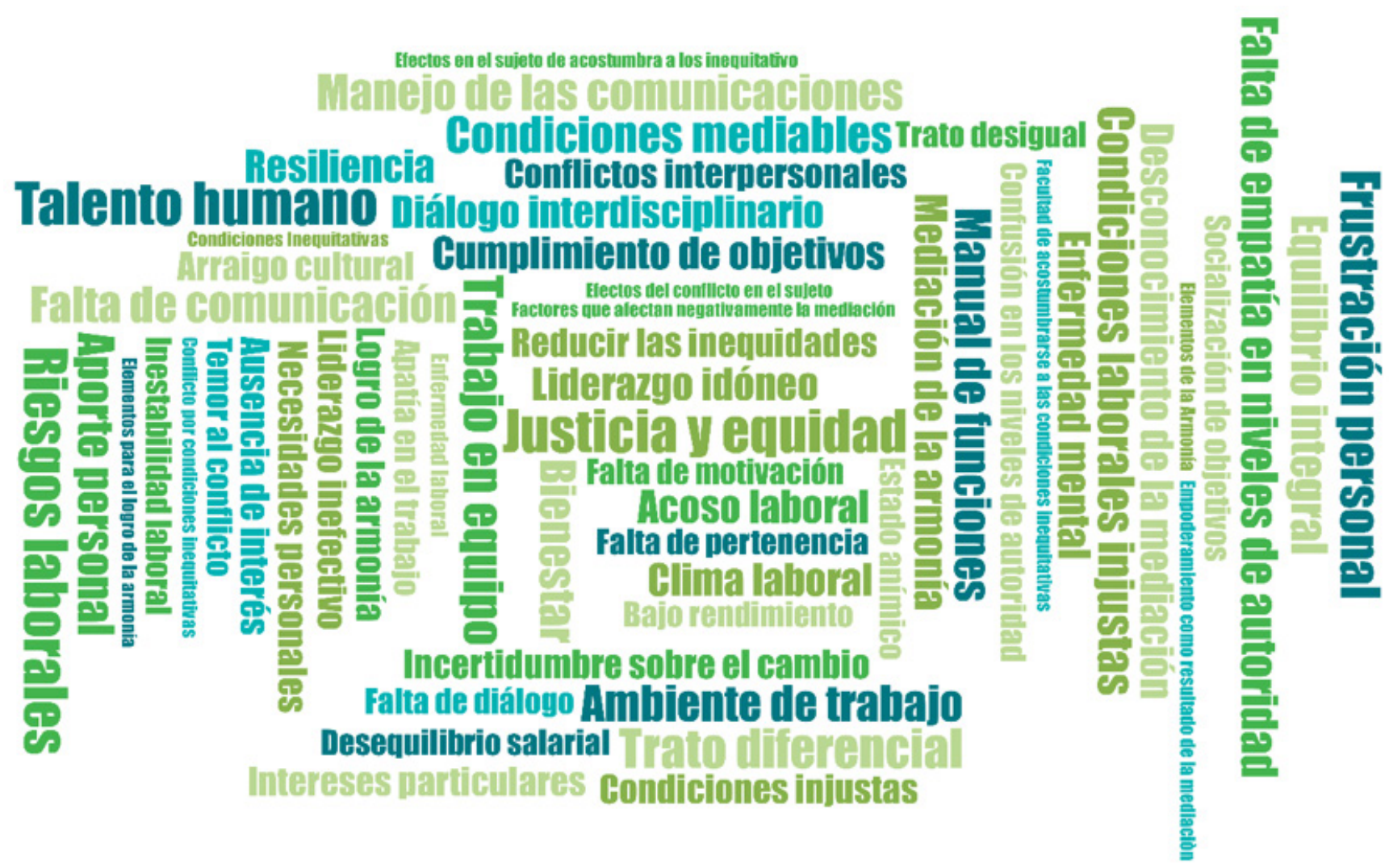

Fuente: Elaboración propia.

La forma como esta nube de palabras destaca elementos considerados clave para los participantes de la investigación, puede analizarse desde tres perspectivas. Inicialmente se ubican aquellos ligados a los procesos organizacionales clave (Herrera, 2013), tales como: talento humano, manual de funciones, manejo de las comunicaciones, riesgos laborales y condiciones laborales; dentro de las entrevistas fue común encontrar apreciaciones referidas a la importancia de consolidar la mediación como parte de estos procesos organizacionales, en algunos casos se hizo referencia a la posibilidad de que se institucionalice como una política de la alta gerencia.

Una segunda perspectiva nos induce al análisis de temáticas asociadas a la cultura organizacional, entendida como una construcción colectiva entre la cotidianidad de los sujetos laborales y lo establecido de manera formal por la alta directiva (González, 2017), tales como: ambiente de trabajo, trabajo en 
equipo, diálogo interdisciplinario, clima laboral, bienestar y acoso laboral; en torno a estos elementos se destacaron argumentos acerca del beneficio colectivo causado por una posible inmersión de la mediación frente a la solución de los conflictos cotidianos, más específicamente, para evitar su escalada.

Una temática muy interesante de analizar fue la cuestión de la percepción de lo inicuo, dado que entra en juego la forma como el sujeto se vincula emocionalmente con ciertas situaciones y el efecto que tiene en su idea simbólica de su rol subjetivo al interior de la organización (Soto, 2019); temáticas como: frustración personal, desequilibrio salarial, justicia y equidad, resiliencia, por mencionar algunas, pone en manifiesto como los sujetos viven de manera cotidiana situaciones que consideran inicuas. Un elemento constante fue la falta de argumentos en torno al manejo de estas condiciones, la generalidad habla de que es una temática que no interesa a la alta dirección, o por lo menos, que no se encuentra visibilizado en normas formales, procesos y/o dinámicas, y, por lo tanto, no se atiende.

\section{CONCLUSIONES Y RECOMENDACIONES}

Esta investigación permitió visibilizar un elemento clave en los conflictos interpersonales laborales: las condiciones inicuas. Sujetos expertos pusieron en contexto lo perjudicial que son estas tanto para el trabajador, como el impacto que tiene en los procesos organizacionales.
Al discursar en torno a la mediación, había un conocimiento básico sobre este mecanismo alternativo, hubo consenso en cuanto al desconocimiento general de su implementación al interior de las organizaciones, para resolver este tipo específico de conflicto; en contraprestación, se le dio protagonismo a la viabilidad de su implementación como método para atender el fenómeno del conflicto laboral interpersonal suscitado por condiciones laborales inicuas.

Un elemento interesante a analizar es la importancia de que la alta gerencia, no sólo apruebe la implementación de la mediación al interior de la organización, sino también de que se cree todo un sistema de soporte, donde este método alterno tenga un lugar dentro de políticas y procesos organizacionales, un lugar que los sujetos puedan reconocer como objetivo e imparcial, donde la filosofía sea el encuentro en el disenso, y que cuente con personal capacitado para tales fines.

Se recomienda avanzar hacia el análisis de viabilidad de la implementación de la mediación de conflictos por condiciones laborales inicuas, por parte de altos directivos y jefes de recursos humanos, así como hacia la descripción de los elementos administrativos y legales que se requerirían para su puesta en escena.

\section{TRABAJOS CITADOS}

Arango, F. (2011). Comunicaciones Corporativas. Cuadernos del Centro se Estudios de Diseño y Comunicación, (35) pp. 17-22. Recuperado en: https://dialnet.unirioja.es/ servlet/articulo?codigo $=5279976$ 
Carrillo Flórez, F. (2020). Pasado, Presente y Futuro de la Conciliación en Carrillo Flórez, F. \& y Gomez Lee, I.D. Los mecanismos alternativos de solución de conflictos en Colombia + MASC. Estudios, Caracterización y Compilación normativa y jurisprudencial. Tomo II: Colección de Fortalecimiento Institucional y Ética, pp. 6-21. Bogotá, Colombia: Procuraduría General de la Nación e Instituto de Estudios del Ministerio Público-IEMP.

Castro Álvarez, F. (2018). Conflicto como motor de cambio y su impacto en la cultura social. Revista Eirene. Estudios de Paz y Conflicto, 1 (1), pp. 61-78. Recuperado en: https://www.estudiosdepazyconflictos.com/index.php/ eirene/article/view/15/4

Cedalise Riquelme, C. (2020). Las Particularidades de la Mediación y el Arbitraje en los Conflictos Laborales Colectivos. En Lugo Serrato, O. P., Gorjón Gómez G.J., Mendizábal Soler, \& y R.C. Cedalise Riquelme, C. La Transversalidad de los MASC. Una Perspectiva México-Panamá (pp. 43-74). México: Editorial Universitaria UANL y Corte Suprema de Justicia de Panamá.

Fernández Massara, M. B. (2016). Mediaciones tecnoeducativas. Consideraciones teóricas a partir de la obra de Jesús Martín-Barbero. Revista Comunicación y Sociedad, (27), pp. 197-220. Recuperado en: http://www. comunicacionysociedad.cucsh.udg.mx/index.php/comsoc/article/view/1771/5489

González Rabanal, M. (2017). Gestión del Cambio Organizacional y Comunicación Interna. Trabajo Individual de fin de Máster. Universidad Pontifica Comillas, pp. 1-65. Recuperado en: https://repositorio.comillas.edu/xmlui/ bitstream/handle/11531/24021/TFM000749.pdf?sequence $=1$ \&isAllowed $=y$

Gorjón Gómez, F. J. (2017). Mediación, su valor intangible y efectos operativos. Una Visión Integradora de los Métodos Alternos de solución de Conflictos. México: Tirant Lo Blanch.

------- (2020). La mediación como vía al bienestar y la felicidad. México: Tirant Lo Blanch.
Hermosilla Pérez, D., Amutio Careaga, A., Da Costa Dutra, S. C, \& y Paéz Rovira, D. (2016). El Liderazgo transformacional en las organizaciones: variables mediadoras y consecuencias a largo plazo. Revista de Psicología del Trabajo y de las Organizaciones Colegio Oficial de Psicologos de Madrid, 32 (3), pp. 135-143. Recuperado en: https://journals.copmadrid.org/jwop/files/articulo20180730124249.pdf

Herrera Caballero, J.M. (2013). El conocimiento en las organizaciones y el bienestar subjetivo. En Lozano Carrillo, O., Espinosa Infante E., \& y Ramírez Faundez, J. Análisis organizacional: aprendizaje e innovación, las organizaciones frente a una concepción del conocimiento, el tiempo y el espacio. pp. 803-834. México, Editorial Hess, Universiadad Autonoma Metropolitana,

Londoño-Proaño, C. (2018). El liderazgo y la comunicación estratégica: una aproximación teórica. Revista Razón y Palabra 22 (3_102), pp. 358-371. Recuperado en: https://revistarazonypalabra.org/index.php/ryp/article/ view/1276/1296

Márquez Romero, R. D., \& Moret Barillas, J. R. (2021). Los empleados como prosumidores: Gestionar la comunicación organizacional con el stakeholder interno. Revista Razón y Palabra, 24 (107), pp. 13-42. Recuperado en: https://www.revistarazonypalabra.org/index.php/ryp/ article/view/1568/1480

Paladines Galarza, F.Y., Valarezo González, K.P., \& Yaguache Quichimbo, J. J. (2013). La comunicación integral, un factor determinante en la gestión de la empresa ecuatoriana. Revista Signo y Pensamiento, (63), pp. 110-128. Recuperado en: https://revistas.javeriana.edu.co/index. php/signoypensamiento/issue/view/549

Paradinas Márquez, M. C. (2019). La comunicación interna como herramienta de prevención y gestión del conflicto en las organizaciones hoteleras. Revista de Ciencias de la Comunicación e Información, 24 (1), pp. 41-57. Recuperado en: http://www.revistaccinformacion.net/index. $\mathrm{php/rcci/article/view/102/67}$ 
Ramón Monje, L. M., \& Gorjón Gómez, F. J. (2019). Armonía organizacional, conflicto y la naturalización de lo inicuo. Revista Eirene. Estudios de Paz y Conflicto, 2 (2), pp. 4360. Recuperado en: https://www.estudiosdepazyconflictos.com/index.php/eirene/article/view/29/14

Ramos, R. D.(2020). Cultura corporativa y su ineludible afectación a la estrategia de talento humano en la prevención de conflictos en grupos organizacionales. Revista Razón y Palabra , 24 (107), pp. 261-281. Recuperado en: https://www.revistarazonypalabra.com/index. php/ryp/article/view/1596/1427

Renecle, M., Gracia, F.J., Tomas, I., \& Peiró, J.M. (2020). Developing Mindful Organizing in Teams: A Participation Climate is not Enough, Teams Need to Feel Safe to Challenge their Leaders. Colegio Oficial de Psicologos de Madrid, Revista de Psicología del Trabajo y de las organizaciones, 36 (3) pp. 181-193. Recuperado en:https://journals.copmadrid.org/jwop/files/1576_5962_ rpto_36_3_0181.pdf

Robles Francia, V. H., Contreras Torres, F., Barbosa Ramírez, D., \& y Juárez Acosta, F. (2013). LIDERAZGO EN DIRECTIVOS COLOMBIANOS VS. MEXICANOS. UN ESTUDIO COMPARATIVO. Investigación y Desarrollo, Revista Latinoamericana de Ciencias Sociales y Desarrollo Humano 21 (2), pp. 395-418. Recuperado en: https://rcientificas.uninorte.edu.co/index.php/investigacion/article/ view/4402/3508

Sáenz López, K.A., \& Tamez, González, G. (2014). Métodos y técnicas cualitativas y cuantitativas aplicables a la investigación en ciencias sociales. México, Tirant Lo Blanch.

Sánchez López, R., \& Cabrera Rojas, I. (2021). Gerencia y responsabilidad social: construcción colectiva desde la complejidad y la acción comunicativa. Telos Revista de Estudios Interdisciplinarios en Ciencias Sociales, 23 (1), pp. 100-114. Recuperado en: http://ojs.urbe.edu/index. php/telos/article/view/3349/4599
Soto Trujillo, C. A. (2019). La facilitación de los procesos de comunicación en la organización: una contribución desde el desarrollo humano al logro de la satisfacción laboral. Investigación y Desarrollo, Revista Revista Latinoamericana de Ciencias Sociales y Desarrollo Humano 27 (2), pp. 57-84. Recuperado en: https://rcientificas.uninorte.edu.co/index.php/investigacion/article/ view/12447/214421444855

Vega Casanova, J., Tapias Hernández, C. A. \& y Pérez Quintero, C.E. (2019). Radio comunitaria y construcción de paz en Colombia. Comunicación, interacción y planeación participativa para el posconflicto. Revista Latina de Comunicación Social, (74), pp. 1391 - 1410. Recuperado en: http://www.revistalatinacs.org/074paper/1390/73es. html

\section{Luz Marina Ramón Monje}

Psicóloga. Magister en Comunicación. Doctoranda en Métodos Alternos de Resolución de Conflictos. Docente Investigadora Universitaria. Email: Iramon@ unisimonbolivar.edu.co 